\title{
Quality of the education system and economic growth. Projections in the case of Morocco
}

\author{
MOHAMED BOUZAHZAH \\ Economics and Management Department \\ Mohammed V University in Rabat \\ United Nations avenue, Agdal, Rabat, B.P:8007.N.U \\ MOROCCO
}

\begin{abstract}
In this paper we use the simulation model developed by Hanushek and Woessman (2011) to assess the economic impact of a reform of the Moroccan education system that would improve the cognitive achievement levels of students, as measured by the PISA score tests. We consider three alternative scenarios to be compared to the economic situation without reform of the education system, referred as "status quo". Our work allows to predict future economic growth that Morroco would achieve through the incremental increase in

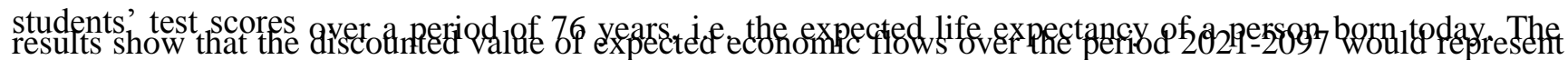
between 149.8 and $718.2 \%$ of Morocco's current GDP, depending on the reform scenarios. Similarly, GDP per capita could be increased by up to 1.89 percentage points per year in the long run. Our results show that the expected economic gains from a reform of the education system would be much greater than its budgetary cost. In the conclusion, several public policies based on these results are discussed.
\end{abstract}

Key-words: - School quality, Education reforms, Human capital, Long run economic growth, Projection Model, Morocco

Received: November 13, 2021. Revised: May 18, 2021. Accepted: May 25, 2021. Published: June 2, 2021.

\section{Introduction}

On a macroeconomic level, significant contributions to the literature have demonstrated a strong relationship between educational variables, productivity, the innovation capacity and the level of economic growth (see [1], [2] and [3]). However, while since the late 1980s, the theoretical and empirical case for the essential role of education in explaining the development of nations has been established, the important question of the size of resources rationally allocated to educational investment remains central, especially for developing countries that have to manage their public finances carefully. Any investment requires a rational trade-off between the overall cost and the expected net gains of human capital accumulation. The same is true at the aggregate level, for the education sector which requires significant budgetary resources.

This trade-off is all the more crucial in a situation of scarce budgetary resources, as in developing countries. Let us recall that this was the central concern of Nobel Prize winner Theodore Schultz [4], who actively supported the economic evaluation of returns in order to convince people of the merits of education in terms of overall productivity. It is therefore easy to understand the numerous contributions that have been made to the rigorous evaluation of private and social economic returns to education ([5]; [6]). Generally, these contributions have as their methodological basis the empirical paradigm of Mincer [7] which allows the estimation of microeconomic returns to human capital from the wage equation, the so-called earnings function. In the same vein, there has been much influential macroeconomics work that has attempted to quantify the overall returns to education in terms of its effects on economic growth ([8]). Nevertheless, some contributions have created considerable controversies and debates as to whether there is even a positive effect of education on economic growth when measuring human capital by its quantitative dimension such as years of schooling. In an interesting and influential article [9], Pritchett even interrogate where education has gone? What was the point of all the large public expenditures on education, especially in developing countries? 
This controversy has had the merit of opening the way for other original research works which consist of turning to other quantifiable dimensions of effective human capital. The authors who initiated this new approach are Hanushek and Woessman [3]. According to these authors, the level of education attained by the populations of an economy remains a rather imprecise measure for quantifying the stock of effective human capital, and consequently, it can induce substantial biases in the analyses of econometric regressions on economic growth. Indeed, the first generation of growth macroeconomics models treated the educational impact on growth in the same way, whatever the country and the features of its education system, whereas it seems obvious that the latter may differ from one country to another. This reflection has naturally led the economic literature to focus on the second dimension of human capital, which is qualitative. Now, it is also the quality of education that matters for the effective measurement of accumulated human capital. The inclusion of the quality of education in the new literature seems to have lifted the veil on the education-growth paradox and has profoundly changed the paradigm of economic development while inspiring educational reform policies.

The emergence of the quality of education approach in the economic literature and debates provides an explanation for several development paradoxes, in particular the examination of economic underperformance observed in Latin American countries between 1960 and 2000, while these countries had a level of education that seemed acceptable in 1960 according to [10]. In policy terms, the consideration of education role as a key factor in the long-term economic growth trajectory indicates implications of great importance [11]. In particular, it tends to put into question the relevance and effectiveness of several education policy recommendations, especially those pursued internationally, which focus on access to education. These policies may ignore the qualitative aspect of education for developing countries, namely the acquisition of cognitive skills required to support socio-economic development.

\section{Economic evaluation of Morocco's education reforms}

The main characteristic of a reform of the education system is that its effects and benefits are not instantaneous. There is a relatively long period of time between the moment of implementation and
Morocco has made significant efforts in recent decades to facilitate access to school for Moroccans, with substantial results, at least in quantitative terms. Growing number of Moroccans are enrolled in the different school cycles. The net primary school enrolment rate has risen sharply. It rose from $36.7 \%$ to $98.92 \%$ between 1971 and 2018. In the same way, the secondary school enrolment rate rose from $11.25 \%$ in 1971 to $80.23 \%$ in 2018 . Finally, the enrolment rate in tertiary education rose from $1.47 \%$ in 1971 to $35.94 \%$ in 2018 . Thus, whatever the quantitative indicator chosen, all point in the same direction; a tremendous improvement in the human capital indicator.

Nonetheless, these improvements have come at the expense of the quality of education. The pupilteacher ratio has been steadily decreasing as the number of pupils has increased. This ratio went from $34.3 \%$ in 1971 to $25.9 \%$ in 2015 . The poor performance of the Moroccan education system is reflected in the low level of cognitive skills acquired by pupils. This observation has been confirmed by several surveys and tests. The results of the 2018 PISA survey showed that the Moroccan education system is one of the weakest in the world. It would be ranked 75th out of 79 countries that participated in this survey. It is ranked lower than almost all the countries of the MENA region concerned by the test.

Over the last two decades, Morocco has included the human capital and training paradigm as a key axis in all its strategic development policies. The idea is to put in place, through reform policies, a Moroccan education system that is efficient and able to respond to the needs for skills and qualifications required by the labour market.

This work proposes to evaluate quantitatively, through a set of simulations, the economic impact of an improvement in school results, i.e. reflecting the quality of education for the case of Morocco. In order to do so, we used the simulation model developed by [12] to quantify the macroeconomic gains that would result from the effective implementation of an education reform that would improve students' cognitive learning levels, as measured by the PISA score tests.

the appearance of the first results. It is therefore interesting to examine how such a reform affects economic conditions over time. For this reason, a projection model seems to us to be an appropriate 
tool for assessing the economic effects of the implementation of a reform of the Moroccan education system. It allows us to trace and quantify the potential gains between the time of its implementation and the time when the reform produces its full effects.

For this purpose, we applied the Hanushek and Woessman model [12] to examine the economic effects of three reforms (scenarios) aiming at improving the quality of Moroccan students' achievements. This projection model has a number of features and is based on several assumptions. For example, we assume that Morocco starts a reform of its education system in 2021 and requires several years to be fully implemented. [12] assume a duration of 20 years for the full implementation of a reform that aims to improve the quality of education. [13] who studied 20 of the world's most successful school systems, argue that any school system can make significant and rapid progress (in less than six years) by putting in place a set of priority levers. Of course, this time frame depends on the initial situation of the system, the ambition, the level and the stated objectives, but also on the political will materialized by the financial resources allocated to this reform.

In any case, we have chosen an intermediate period of 10 years for this study. We also assume that the improvement in the quality of education does not translate into a mechanical improvement in the quality of the labour force. It improves gradually and becomes more productive as it is replaced by workers from the new education system. The speed

\subsection{Increasing the Annual Growth Rate in the Different Phases}

Phase 1 (2021-2030). This 10-year phase is the period during which the reform of the education system is implemented. We assume that this implementation is linear. If, for example, the reform allows the PISA score of Moroccan students to improve by 50 points at the end of the decade, this means that each year the score achieved by Moroccan students improves by 5 points. This hypothesis is not unrealistic, given that such a reform must involve, for example, continuous training or a gradual replacement of teachers. This linear trajectory determines the quality of the new cohorts of workers at each moment.

Thus, during this first phase of implementation, the additional growth rate of GDP per capita at the date $t$ generated by the reform, noted $\Delta^{t}$ is given by with which the labour force is renewed depends on how long people have been working. If we consider that the average age of entry into the labour market is 20 years, and that the legal retirement age is 60 years, the active period is 40 years. Concerning the time horizon of the effects of the reform, it depends on the life expectancy of an average Moroccan born in 2021, date of the beginning of the implementation of the reform. This life expectancy is approximately 77 years. Economic developments will therefore be examined between 2021 and 2097. The principle is to compare along this horizon the GDP, if the status quo is maintained, with what this GDP would be if a reform is implemented in 2021. Without reform of the education system, GDP per capita is assumed to grow at its long-term potential growth rate. When a reform is implemented, GDP per capita grows at a higher rate than the potential growth rate. The magnitude of this additional growth depends on the link between the quality of the education system and economic growth, measured by a growth coefficient. Moreover, this additional growth rate, linked to the improvement in quality, is variable over time, insofar as the improvement in the quality of the labour force takes place gradually. Over time, and as new cohorts that have benefited from the new education system enter the labour market, the average quality of the labour force increases.

The projection horizon, 2021-2097, is divided into several phases according to the level of the additional growth rate of GDP per capita.

$\Delta^{t}=G C \times \Delta P I S A \times \frac{1}{\text { Working Life }} \times \frac{t-2021}{10}+\Delta^{t-1}$

where $G C$ is the growth coefficient, $\triangle P I S A$ is the increase in the average PISA score due to the reform. The term working life allows for the fact that each cohort performing better as a result of the reform representing only part of the working life. Finally, the term $\frac{t-2021}{10}$ is justified by the fact that the effective duration of the reform is 10 years.

Phase 2 (2031-2060). In this phase, the reform is fully implemented, all students reach the new level, but as the working life is 40 years, there are still workers with initial skill levels who are replaced in retirement by better performing workers.

The additional growth rate of GDP per capita at date $t$ generated by the reform is now given by 


$$
\Delta^{t}=G C \times \Delta P I S A \times \frac{1}{\text { Working life }}+\Delta^{t-1}
$$

Phase 3 (2061-2070). In this phase, the first 20 labor market cohorts, which only benefited partially from the education reform, are replaced by cohorts that benefited fully from the adopted education reform. The additional growth rate is given by

\subsection{Changes in GDP with and without Reform}

As outlined above, the principle is to compare the evolution of GDP in the presence of a reformed education system with what it would be if things remained as they are today.

\section{Evolution of GDP in the absence of reforms:}

In the absence of an education reform, GDP (noted $\left.G D P_{N R}^{t}\right)$ evolves at its long-term potential growth rate $\left(g_{p}\right)$.

$$
G D P_{N R}^{t}=G D P_{N R}^{t}\left(1+g_{p}\right)
$$

\section{Evolution of GDP in the presence of a reform:}

In the presence of a reform, GDP (denoted $G D P_{R}^{t}$ ) increases with the potential growth rate, increased by the additional growth rate $\Delta^{t}$ :

$$
G D P_{R}^{t}=G D P_{R}^{t}\left(1+g_{p}\right)+\Delta^{t}
$$

\section{The total effect of the reform:}

\section{Parameterization of the Model}

The implementation of the model requires setting the values of the parameters. We have already set the values of some of them. The time needed for a full implementation of the reform, let us recall, has been set at 10 years and the improvement of the system is linear. The working life is 40 years; each new cohort of workers represents $2.5 \%$ (1/40) of the working population. Once the education reform is implemented, it takes 40 years for the entire labor force to reach the new skill level. The life expectancy of a Moroccan born in 2021 is 77 years.

The other parameters to be calibrated and specified are the growth coefficient ( $G C)$, the potential economic growth rate $\left(g_{p}\right)$ and the social discount rate $(\rho)$.

$$
\begin{aligned}
\Delta^{t}=G C \times \Delta P I S A & \times \frac{1}{\text { Working life }}\left(\Delta^{t-40}-\Delta^{t-41}\right) \\
& +\Delta^{t-1}
\end{aligned}
$$

Phase 4 (2071-2097). Finally, the entire workforce has passed through the reformed education system. The annual growth rate is now increased by the long-term constant growth effect $\Delta$ :

$$
\Delta=G C \times \Delta P I S A
$$

The economic benefits of education system reform accrue at different times in the future. It is trivial that more immediate benefits are both more valuable and more certain than those far into the future. Moreover, such a reform is a genuine public investment, and from this point of view, its benefits are spread over time while its cost is immediate, or at least spread over a shorter period. Assessing the net gain of the reform requires comparing the cost of the reform with its cumulative benefits converted into a present value.

Thus, the total (gross) value of education reform (TVER) is given by the sum of the present values of the annual differences between GDP with reform and GDP without reform

$$
T V E R=\sum_{2021}^{2097}\left(G D P_{R}^{t}-G D P_{N R}^{t}\right) \times(1+\rho)^{-(t-2021)}
$$

In this equation, $\rho$ is the social discount rate.

The potential growth rate of GDP per capita is calculated on the basis of a smoothing by the Hodrick-Prescott filter applied to GDP per capita over 25 years (1995-2019). Over this period, it is $2.5 \%$ on average per year.

The most important parameter, to which the results should be very sensitive, is the growth coefficient. [14] show that an improvement in the PISA score in mathematics of 47 points increases the growth rate of GDP by one percentage point. For the 24 OECD countries, [12] estimate this coefficient at 1,864 , which is converted into 0.932 percentage point improvement in GDP per capita in the long run following 50points increase in PISA score. [11] show that 1 point increase in standard deviation, which corresponds to a score improvement of 100 points, increases the GDP growth rate by 2 points. 
From our side, we set it at 1.5 in the central scenario.

The value of the discount rate is one of the most important parameters. The greater the preference of individuals for the present, the smaller the net economic gain from reform. The standard value of the social discount rate used in long-term projections of the sustainability of pension systems and public finances, for example, is 3\% ([15] ; [16]. In France, The General Commissionership of Plan, when it still existed, set this rate at $4 \%$ in 2005. In Germany, it is $3 \%$ and in the United Kingdom $3.5 \%$. It may be thought that economic agents in developing countries are characterized by a form of myopia and that the preference for the present is higher, so this rate would also be higher. In this context, [17], for 9 Latin American countries, recommends a rate between $5 \%$ and $6 \%$. For Africa, [18] shows that this rate is $5.3 \%$ for Namibia and [19] find the rate to be between $8 \%$ and $9 \%$ for Senegal.

In our case, we use the Ramsey rule in certain universe to estimate the value of the social discount rate for Morocco. It is written as follows

$$
\rho=\delta+\gamma \times \mu
$$

In this equation $\delta$ is the rate of pure preference for the present, $\gamma$ is the marginal utility elasticity of consumption and $\mu$ is the growth rate of per capita consumption.
The rate of pure preference for the present can be approximated, following, among others, [20] and [21], by the gross mortality rate. In Morocco, this rate is decreasing. Between 1960 and 2018 it was equal to $0.96 \%$ and between 2000 and 2018 is $0.55 \%$. The elasticity of marginal utility of consumption measures the percentage decrease in the marginal utility of consumption resulting from a $1 \%$ increase in consumption. Like [22], this parameter can be estimated by observing the saving behavior of individuals. In this case, it is given by:

$$
\gamma=\frac{i-\delta}{\frac{S}{Y}(i-\omega)+\omega}
$$

where $i$ is the rate of return on investment which we approximate by interest rate oflending in banking sector, $\delta$ the rate of pure preference for the present, $\frac{S}{Y}$ the savings rate and $\omega$ the growth rate of labour income. The data on savings, national income and growth rate of per capita income are taken from the World Bank database [23]. The interest rate is the average interest rate on customer loans granted by banks over the period 2008-2017 and is taken from the Central Bank database, it is $6.04 \%$.

The following table summarizes the used data and shows that the calibrated value of the marginal elasticity of consumption is between $1.71 \%$ and $8.31 \%$.

Table 1. Calibration of the marginal utility elasticity of consumption

\begin{tabular}{lcc}
\hline Parameters & Estimate1 & Estimate2 \\
\hline Savings rate $\left(\frac{S}{Y}\right)$ & $20.00 \%$ & $6.00 \%$ \\
Interest rate $(i)$ & $6.04 \%$ & $10.42 \%$ \\
Growth rate of GDP per capita $(\omega)$ & $2.50 \%$ & $1.81 \%$ \\
Rate of preference for the present $(\delta)$ & $0.55 \%$ & $0.90 \%$ \\
Marginal utility elasticity of consumption $(\boldsymbol{\gamma})$ & $\mathbf{1 . 7 1 \%}$ & $\mathbf{4 . 0 9 \%}$ \\
\hline
\end{tabular}

It is now possible, considering the previous estimates, to calibrate the value of the social discount rate. Based on the mortality rate used, it is between $4.83 \%$ and $8.31 \%$. We have retained the intermediate value of $6 \%$.

Table 2. Calibration of the discount rate

\begin{tabular}{lcc}
\hline Parameters & Estimate 1 & Estimate 2 \\
\hline Marginal utility elasticity of consumption $(\gamma)$ & $1.71 \%$ & $4.09 \%$ \\
Rate of preference for the present $(\delta)$ & $0.55 \%$ & $0.90 \%$ \\
Growth rate of GDP/capita $(\omega)$ & $2.50 \%$ & $1.81 \%$ \\
Discount rate $(\boldsymbol{\rho})$ & $\mathbf{4 . 8 3 \%}$ & $\mathbf{8 . 3 1 \%}$ \\
\hline
\end{tabular}


A major uncertainty covers the two previous parameters. A sensitivity study will be made to test

\section{Selected Scenarios and results of the projections}

In this section we evaluate the economic impacts of a reform of the Moroccan education system under different scenarios. We consider three alternative scenarios to be compared to the economic situation without reform of the education system, referred as "status quo".

The first alternative scenario "basic skills" consists of a minimum reform, which consists of conducting a reform that would allow Moroccan students to acquire the skills to achieve a minimal level of competences, which is defined here as obtaining a score of 400 in the PISA tests. Morocco's score would improve by 32 points from 368 to 400, an improvement of $1 / 3$ standard deviation. As a result, Morocco would improve its ranking from 74th to 67 th place. the robustness of the results.

The second alternative scenario "PISA Jordan level", which is very accessible, aims to provide Moroccan students with the same achievements as Jordanian students. It means that Morocco's average score will rise by 50 points and move it up 18 places in the ranking of the best education systems.

The third alternative scenario "PISA France level", which is very ambitious, should give the Moroccan education system the same quality as the French one. In this context, the reforms should be constructed in such a way that allow an improvement of 126 points.

The table summarizes the characteristics of the different scenarios.

\begin{tabular}{lcccc}
\hline & $\begin{array}{c}\text { Scenario 0. } \\
\text { "Status quo" }\end{array}$ & $\begin{array}{c}\text { Scenario 1. } \\
\text { "Basic skills" }\end{array}$ & $\begin{array}{c}\text { Scenario 2. } \\
\text { "PISA Jordan } \\
\text { level" }\end{array}$ & $\begin{array}{c}\text { Scenario 3. } \\
\text { "PISA level } \\
\text { France" }\end{array}$ \\
\hline Reading & 359 & 400 & 419 & 493 \\
Score and (rank) & $(74)$ & $(66)$ & $(56)$ & $(24)$ \\
\hline Mathematics & 368 & 400 & 400 & 495 \\
Score and (rank) & $(74)$ & $(65)$ & $(64)$ & $(25)$ \\
\hline Science & 377 & 400 & 438 & 493 \\
Score and (rank) & $(74)$ & $(66)$ & $(48)$ & $(25)$ \\
\hline Average score & 368 & 400 & 419 & 494 \\
score and (rank) & $(74)$ & $(67)$ & $(56)$ & $(26)$ \\
\hline
\end{tabular}

The economic effect of education reform under the first scenario is presented in Figure 1, which summarizes the marginal impact on GDP for each year in the future.

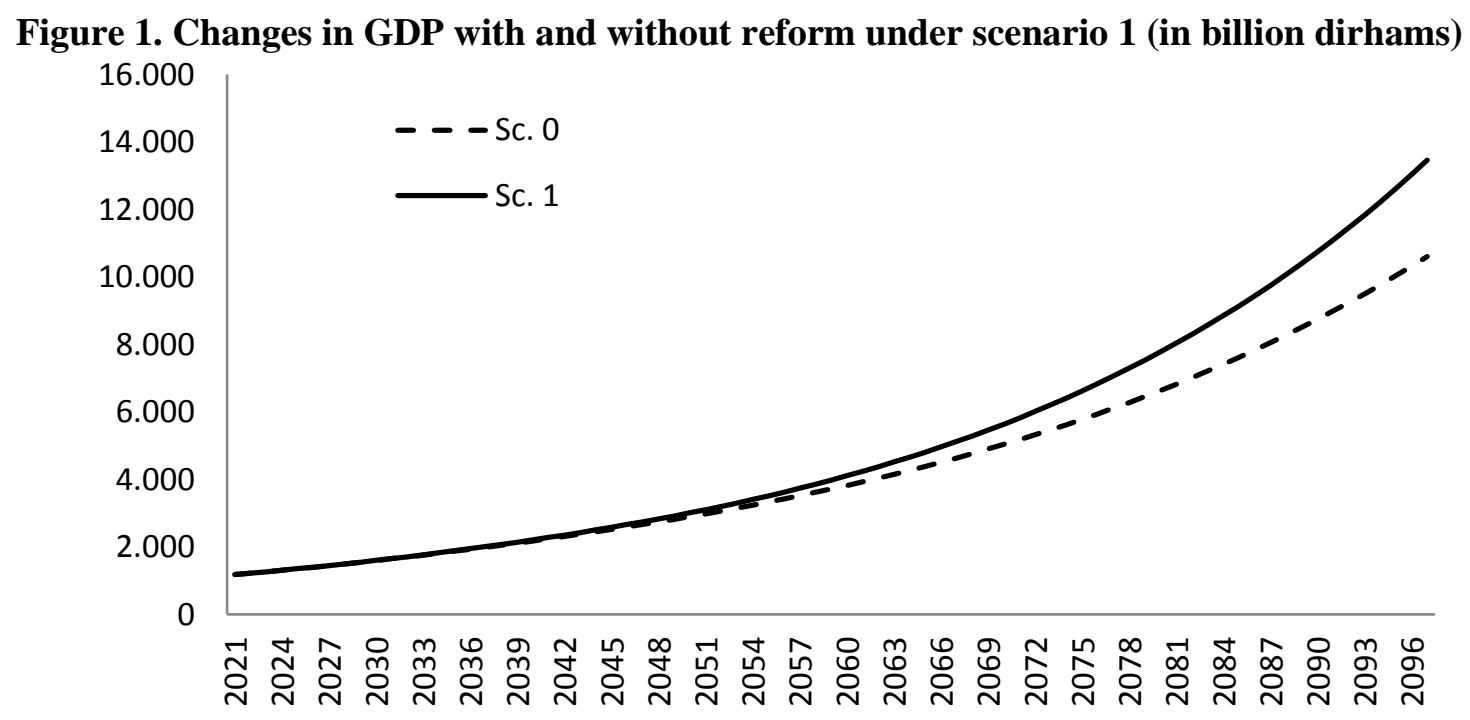


Although there is no initial impact until the best performing students start to become more important in the labor market, GDP will be $3.5 \%$ higher than it would have been expected without an improvement in human capital by 2049. In 2066, GDP per capita in the presence of minimal reform is expected to be $26.9 \%$ higher than GDP per capita if the status quo is maintained. In terms of growth rate, while in the absence of the reform, GDP per capita grows annually at a rate of $2.5 \%$, in the long run, when the labor force is composed only of workers with better skills, it would be increased by an additional 0.48 percentage points. Meanwhile, between 2021 and 2055, for example, GDP per capita would increase annually by an average of $2.66 \%$ and between 2055 and 2097 by $2.96 \%$.

In terms of real GDP, in the first years after the reform, the gains are modest. However, as students from the new education system enter the labor market, productivity increases and the gains become more and more significant. For the year 2049 only, for example, Morocco would gain 19 billion dirhams with the reform. Once the reform will have produced all its effects, this gain will rise to 34 billion dirhams for the year 2097 .

In order to fully evaluate the reform, it is necessary to examine the overall economic value of the reform, i.e. the cumulative gains over the entire period. In 2055, this value would be 335.35 billion dirhams, which would represent $28.4 \%$ of the current GDP. It would be 1,770.1 billion dirhams, which would represent $149.9 \%$ of current GDP. This means that as long as this minimum reform costs less than 335.35 billion dirhams, it is economically profitable. It is rational to assume that no reform, despite how ambitious is, can cost that much.

\section{Scenario 2: "PISA Jordan level"}

Some might argue that the quality of education in some Asian or Scandinavian countries is linked to cultural, institutional or other factors, which Morocco lacks. In short, a country like Morocco could not significantly improve its education system. This could discourage any attempt in this direction. On the other hand, if countries more or less similar to Morocco, in some respects, have succeeded in improving their education systems, this could constitute a real driving force and an additional motivation to embark on this path. One of the few Arab and MENA countries present in the latest PISA ranking is Jordan. This country is largely better ranked than Morocco. It is a country quite similar to Morocco in cultural and institutional terms. In 2018, Morocco's GDP per capita was $76.3 \%$ of Jordan's GDP per capita. In this section we examine the economic gains of a reform that would aim to bring the level of Moroccan students up to that of Jordanian ones. This means that Morocco would improve its score by 51 points and move its ranking from 74th to 56th place out of 78 countries. This reform is $a$ priori affordable, but as we shall see, the economic gains are significant.

The following graph shows the evolution of GDP without reform and GDP with reform under scenario 2. Here again, if the benefits of the reform are not apparent during the first years due to the time needed for its implementation and the progressive renewal of the labor force, the longterm effects seem to be very significant.

\section{Figure 2. Changes in GDP with and without reform under scenario 2 (in billion dirhams)}

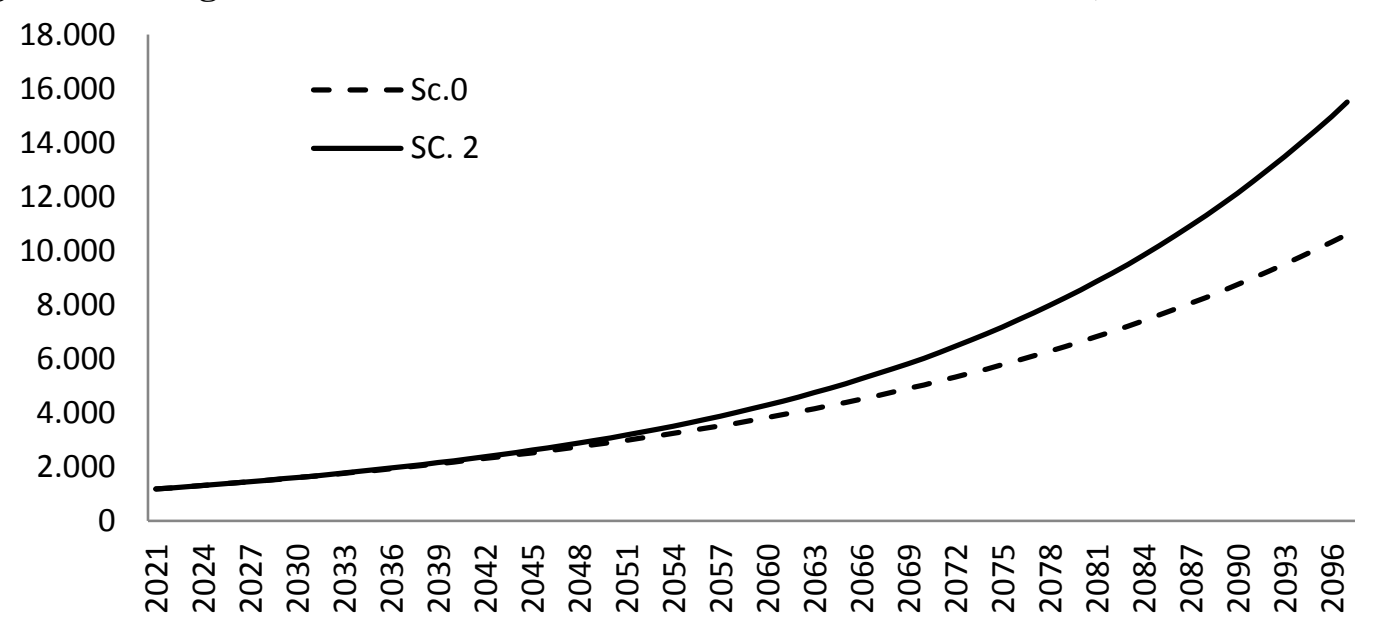


In the long term, through this reform, the growth rate of Morocco's GDP per capita would increase by 0.77 percentage points. The potential growth rate would then increase from $2.5 \%$ to $3.27 \%$. After 20 years, GDP per capita would be $6 \%$ higher than it would have been without reform. Over time, as the share of those who have benefited from the new education system is larger in the Moroccan workforce, the effects on income are more pronounced and the living conditions of Moroccans are better. In 2070, an average Moroccan would earn 130.46 thousand dirhams in the case of a Jordanian-style reform of the education system, compared to 109.08 thousand dirhams if the status quo is maintained, which represents an improvement of $19.6 \%$. In the long run, when the entire labor force is renewed, the gains would be more obvious. In 2097, the GDP per capita in Morocco would be 310.6 thousand dirhams if the reform is adopted, which would put Moroccan students at the same level as Jordanian students. This GDP, if no measures in the field of education are adopted, would be at the same time only 212.4 thousand dirhams. This reform, which we have emphasized seems very accessible, would make it possible to improve the standard of living for Moroccans by more than $46.2 \%$.

The reform generates gains every year. And each year, these gains are greater than those of the previous year. By 2055, the discounted cumulative gains of the reform come to 539 billion dirhams, which already represents $45.6 \%$ of the current GDP. By 2097, the discounted cumulative gains would amount to $2,840.7$ billion dirhams and represent $240.5 \%$ of current GDP. It is not necessary to make a cost-benefit calculation to realize that this investment in the reform of the education system is largely profitable. No reform would cost $45.6 \%$ of GDP, not to mention $240.5 \%$ of GDP.

\section{Scenario 3: 'PISA France level'.}

Several countries (Poland, Italy, etc.) have succeeded in improving significantly their ranking in the various tests in a few years. Between 2000 and 2012, Poland, for example, succeeded through a series of reforms in moving, well above the OECD average, to 14 th place worldwide. In almost a decade, it has gone from 490 points in mathematics, a score below the European average, to 518 points, on this one above the European average. There are many more examples of countries that have achieved these accomplishments. Improving the quality of an education system very significantly, and in a short time, is nothing extraordinary if the political will exists and substantial financial resources are mobilized ${ }^{1}$.

This scenario examines the effects of an ambitious reform that would bring the level of Moroccan students to that of French students. It would generate a significant qualitative leap in the Moroccan education system, which would raise the score of Moroccan students from 382 to 494 and thus, would position Morocco in 26th place in the world. Such a reform would probably be very costly, but as we shall see, its economic gains are very significant (Figure 3 ).

The long-term improvement in the standard of living of Moroccans would be very substantial. The educational reform would increase the long-term growth rate of Moroccan GDP per capita by 1.89 percentage points, it would be $4.39 \%$. Yet, this cruise rate is only reached starting from 2071.

\footnotetext{
${ }^{1}$ In a 2015 OECD report, the authors note that results obtained in the PISA surveys has shown that it is possible to progress much faster than previously thought.
} 


\section{Figure 3. Changes in GDP with and without reform under scenario 3 (in billion dirhams)}

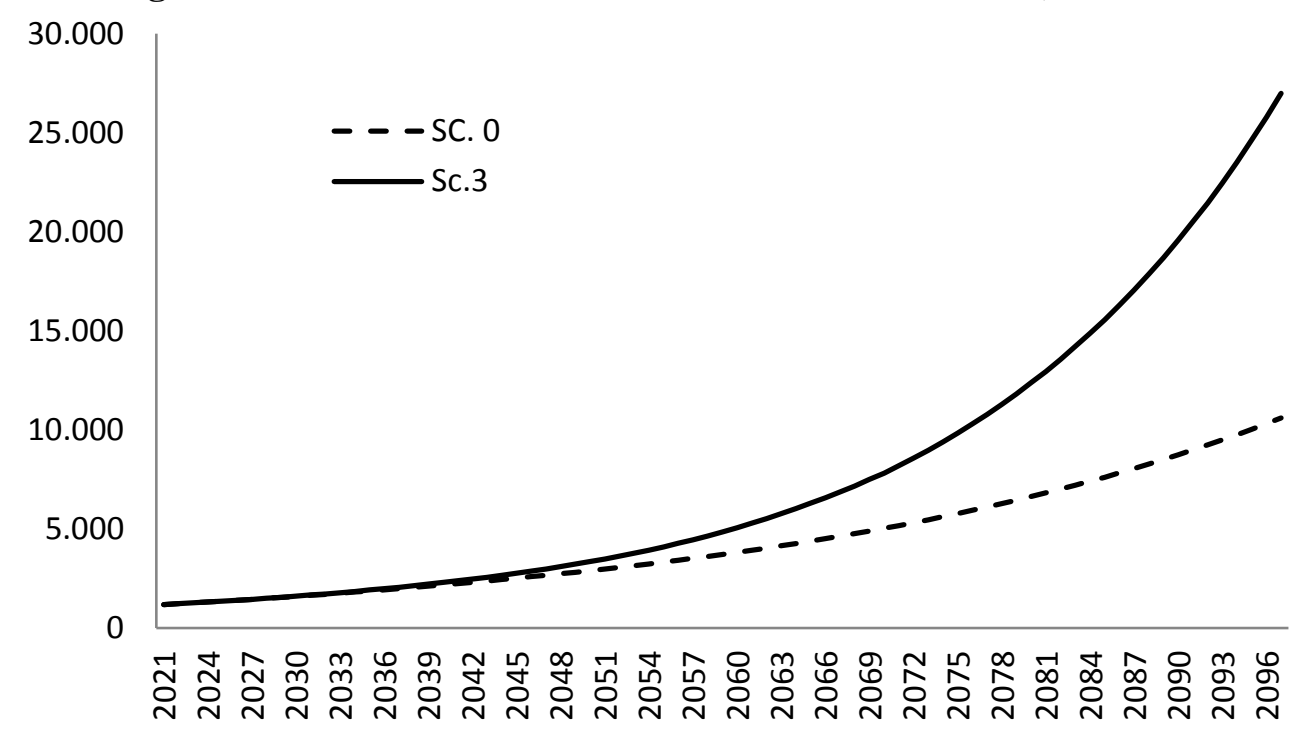

By 2041, i.e. two decades after the implementation of the reform, the GDP per capita would be more than $6.2 \%$ higher than what it would have been without the reform. An average Moroccan would earn 56.63 thousand dirhams against 53.3 thousand dirhams. From 2055, the standard of living of Moroccans would improve by more than $23.16 \%$ compared to the status quo. At the end of the considered horizon, in 2097, the GDP per capita of the average Moroccan would be 2.5 times higher than what it would have been without education reform. It would be 540.73 thousand dirhams in the case of a reform that would succeed in bringing the level of Moroccan pupils to the same level as French pupils, against 212.46 thousand dirhams if the status quo is maintained. In terms of real GDP, it would be $26,987.29$ billion dirhams in the first case against $10,603.91$ billion dirhams in the second case.

Regarding the benefits of this reform, and within the framework of a cost-benefit analysis, the estimate of the economic value of the reform shows that the cumulative discounted gains would amount to $1,377.85$ billion dirhams in 2055 , which would represent $116.65 \%$ of the current GDP, i.e. at the time of the financing of the reform, and to $8,482.93$ billion dirhams, which would represent $718.20 \%$ of the current GDP.

The results of the three reforms are summarized in Table 4.

Table 4. Economic impacts of the different reforms

\begin{tabular}{lccc}
\hline & $\begin{array}{c}\text { Scenario 1. } \\
\text { "Basic skills" }\end{array}$ & $\begin{array}{c}\text { Scenario 2. } \\
\text { "PISA level } \\
\text { Jordan" }\end{array}$ & $\begin{array}{c}\text { Scenario 3. } \\
\text { "PISA level } \\
\text { France" }\end{array}$ \\
\hline Additional long-term growth rate (in \%) & 0.48 & 0.77 & 1.89 \\
\hline GDP growth in 2055 (in \%) & $\mathbf{5 . 4 5}$ & $\mathbf{8 . 8 2}$ & $\mathbf{2 3 . 1 6}$ \\
\hline Average annual increase in GDP between 2021 and 2055 (\%) & 2.66 & 2.76 & 3.13 \\
\hline CDV in 2055 (in billion dirhams) & 335.35 & 539.04 & $1,377.85$ \\
\hline As \% of GDP 2021 & 28.39 & 45.64 & 116.65 \\
\hline GDP growth in 2097 (in \%) & $\mathbf{2 6 , 9 4}$ & $\mathbf{4 6 , 1 9}$ & $\mathbf{2 5 4 , 5 0}$ \\
\hline Average annual increase in GDP between 2056 and 2097 (\%) & 2.96 & 3.23 & 4.30 \\
\hline CDV in 2097 (in billion dirhams) & $1,770.13$ & 2.840 .74 & $8,482.93$ \\
\hline As \% of 2021 GDP & 149.87 & 240.51 & 718.20 \\
\hline
\end{tabular}

CDV: Cumulative Discounted Value

We spoke above of alternative scenarios, but in reality, it is a progression of reforms. The most important reform, the one that would allow a significant improvement in the living standards of
Moroccans in the long term, is a series of reforms, spread over a few years, of the education system. The idea is that a first reform would bring us to the 
basic level, a second series to the level of Jordan and a third to the level of France.

\section{Analysis of robustness of the main results}

Even in the case of a minimum reform, the benefits seem very important. As we have seen in the case of scenario 1, the gross benefit of the reform is $28.39 \%$ of GDP by 2055 and $149.87 \%$ of current GDP by 2097. However, these results are subject to an uncertainty linked to the uncertainty of the values of the parameters fixed by the calibration procedure, in particular with regard to the growth coefficient and the social discount rate. It should be remembered that we set the growth coefficient at 1.5 and the social discount rate at $6 \%$.

We examine here the sensitivity of the results, in particular the cumulative discounted value of the reform, which is in fine the criterion for deciding on the profitability of the public investment that the reform of the quality of the education system represents. In addition to the central variant, we considered two other alternative variants. For these alternative variants we have assumed that the growth coefficient is equal to 1.3 and 1.0 and that the social discount rate takes the values $7 \%$ and $8 \%$.

The table 5 summarizes the three variants:

Table 5. Summary of variants in the sensitivity study

\begin{tabular}{lccc}
\hline & Variant 1 & Variant 2 & Variant 3 \\
\hline Growth coefficient & 1.5 & 1.3 & 1.0 \\
Discount rate & $6.0 \%$ & $7.0 \%$ & $8.0 \%$ \\
\hline
\end{tabular}

The results of the projections under the three variants are presented in the table 6 . It shows that the economic gains of the different education reforms are very sensitive to the values of the chosen parameters; the CDV varies from simple to quadruple. In the case of a minimum reform (scenario 1), the gain goes from 1,770.1 billion dirhams under variant 1 to 473.9 billion dirhams under variant 3 . For a reform to be profitable, the cost must not exceed $149.7 \%$ of GDP in the first case and only $40.1 \%$ in the second. The volatility of results is also identical in the case of the other scenarios. Gains vary from $2,840.7$ to 748.2 billion dirhams in the case of scenario 2 and fall from $8,482.9$ to $2,073.3$ billion dirhams in the case of scenario 3 .

Table 6. Summary of CDV of different reforms based on different variants

\begin{tabular}{lccc}
\hline & Variant 1 & Variant 2 & Variant 3 \\
\hline Scenario 1 & $\mathbf{1 , 7 7 0 . 1}$ & $\mathbf{9 5 9 . 4}$ & $\mathbf{4 7 3 . 9}$ \\
& $(149.7 \%)$ & $(91.2 \%)$ & $(40.1 \%)$ \\
Scenario 2 & $\mathbf{2 , 8 4 0 . 7}$ & $\mathbf{1 , 5 2 7 . 0}$ & $\mathbf{7 4 8 . 2}$ \\
& $(240,5 \%)$ & $(129.3 \%)$ & $(63.3 \%)$ \\
Scenario 3 & $\mathbf{8 , 4 8 2 . 9 3}$ & $\mathbf{4 , 4 0 6 . 6}$ & $\mathbf{2 , 0 7 3 . 3}$ \\
& $(718.2 \%)$ & $(373.1 \%)$ & $(175.5 \%)$ \\
\hline
\end{tabular}

The values between (.) indicate the share of current GDP represented by the economic value of the reform.

Some might argue that the results obtained are dependent on the choice of values for certain parameters. This uncertainty in the results led us to choose the least optimistic case. We have examined the case of the basic reform (scenario 1) which can be considered as a first step in a more ambitious reform, for different values of the growth coefficient and the social discount rate.

The results of the simulations are summarized in the graph below.

\section{Figure 4. Sensitivity of the economic value of the reform to changes in the growth coefficient and the} social discount rate 


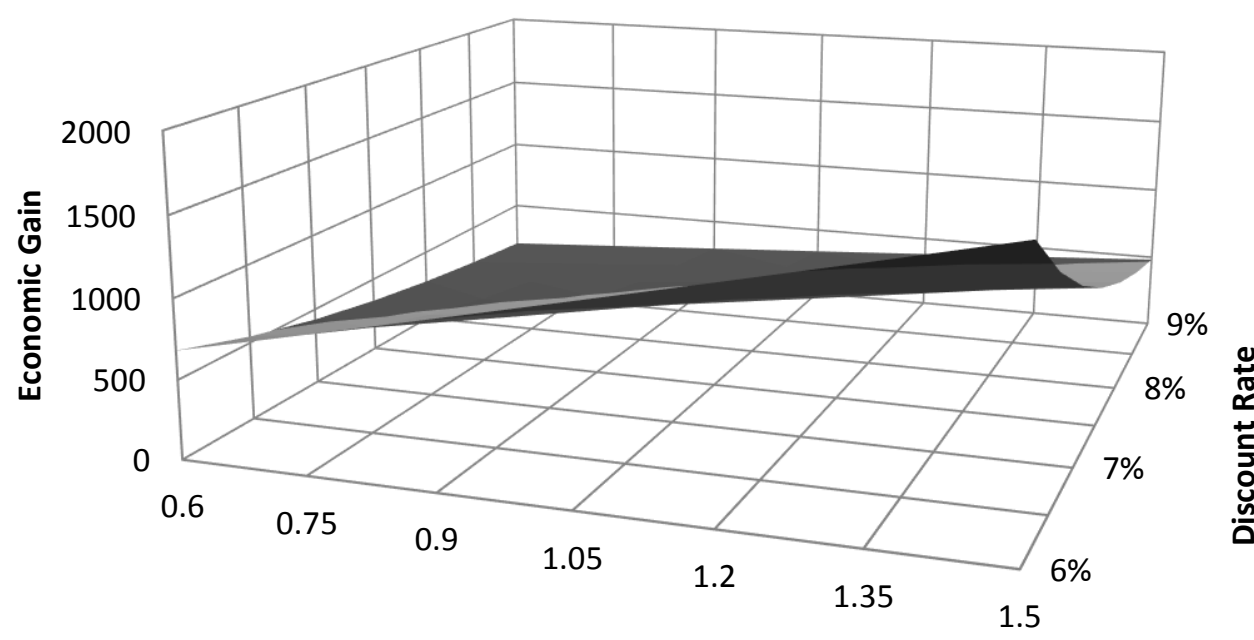

Growth Coefficient

Needless to say, as expected, the economic gain decreases as the growth coefficient decreases and the discount rate increases. Note that we have considered a growth coefficient that varies from 0.6 to 1.5 and a discount rate ranging from $6 \%$ to $9 \%$. For a discount rate of $6 \%$, the gains vary from 682.2 billion dirhams to $1,770.1$ billion dirhams. For a discount rate of $9 \%$, the gains vary from 187.6 to 482.3 billion dirhams. Thus, the minimum economic gain linked to a basic reform of the Moroccan education system is of the order of 167.6 billion dirhams, which represents $15.9 \%$ of current GDP. This means that unless this basic reform exceeds this amount, it remains beneficial for the country.

\section{Conclusion}

The issue of reforming the education system in Morocco must be made a priority. Despite the authorities' desire to do so for several decades, the Moroccan education system continues to perform poorly. The causes of these failures are multiple and complex and stem from the accumulation of several factors; political, economic, historical and cultural. The Moroccan Higher Education Council [24], for example, has provided several explanations for these failures. These include the non-generalization of pre-school, repetition, the learning conditions offered by the school, such as infrastructure, class size, pedagogical resources and teachers' workload. Other works point out to problems related to language incoherence [25]. [26] Akesbi (2015) has identified shortcomings and limitations in the management of the sector. Thus, a number of dysfunctions have been noticed at the level of the Ministry of Education, colleges or
Hence, even considering the most unfavorable scenario, i.e. the least ambitious reform of the education system and considering the least favorable parameter values, the opportunity cost of the status quo is enormous. Indeed, maintaining the status quo means an opportunity cost, a loss of revenue in terms of GDP, of about $16 \%$. This is much higher than the cost of a minimal reform. On the other hand, the discounted gain of this reform, considering realistic conditions $(7 \%$ for the discount rate and 1 for the growth coefficient), is of the order of 767.6 billion dirhams, i.e. $65 \%$ of the current GDP.

regional institutions. These include centralized management of public education contracts, lack of management of public education contracts, lack of organized and systematic external control of colleges and delegations, backlog in school construction, lack of competition between companies and fast deterioration of reconstructed schools. The author also conducted several focus groups with national education stakeholders and identified some problems. At the level of students and parents, problems such as overcrowded classes, frequent teacher absences, lack of extracurricular activities, poor and inadequate infrastructure, and problems with course support were identified. With regard to school principals, they mainly mentioned problems related to their inability to manage human resources at the threshold of the failure rate set by the school map, the lack of autonomy of schools and their 
difficulty in taking initiatives. The Moroccan education system also suffers from certain shortcomings that are necessary for an efficient system. Recent specialized literature highlights, for example, the role of new technologies used in the construction of new learning [27] or the establishment of conditions for sustainable development of educational institutions, through the development of the conceptual basis of control over the provision of information and communication [28]. Finally, preschool in Morocco is still at an embryonic stage. However, recent work shows that its generalization and the improvement of its quality is a determining factor in the improvement of the educational system [29].

This quick overview shows that the challenges are great and that reforming the education system would require significant budgetary resources. However, the results of our simulations clearly show that the benefits of an education reform, which would improve the skills of Moroccan students, are so large that they would outweigh any cost, despite how exorbitant is, required for an education reform.

\section{References:}

[1] Barro, R.J. Economic Growth in a cross section of countries, Quarterly Journal of Economics, Vol.151, 1991, pp.407-443.

[2] Mankiw, N., Romer, D., \& Weil, D. A contribution to the empirics of economic growth, Quarterly Journal of Economics, 107, 1992, pp.407-437.

[3] Hanushek, E.A. \& Woessmann, L. The role of cognitive skills in economic development, Journal of Economic Literature, Vol.46, No.3, 2008, pp. 607-68.

[4] Schultz, T.W. Investment in Human Capital, The American Economic Review, Vol.LI, No.1, 1961, pp. 1-17.

[5] Card, D. Empirical Strategies in Labor Economics, in Handbook of Labor Economics, Volume 3A, ed. by Orley. 1999.

[6] Psacharopoulos, G. \& Patrinos, H. Returns to Investment in Education: A Further Update, Education Economics, Vol.12, No.2, 2004, pp. 111-134.

[7] Mincer, J. Schooling, Experience, and Earnings, Columbia University Press, New York. 1994.
In addition, in a 2015 publication, the OECD looked at the countries that have improved their ranking the most since 2000, including Germany, Brazil, Greece, Italy and Mexico. The first findings are that improving of the results is possible regardless of the level of national wealth, culture or geographical location. It is also possible to combine the search for excellence with equity in the education system. The evolution of the results obtained in the PISA surveys has shown that it is possible to progress much faster than previously thought. This is illustrated by Poland, which in ten years has gone from a score of 490 points in mathematics, which is below the European average, to 518 points, above the European average. The countries that are making progress are mainly those that manage to reduce the percentage of lowperforming pupils. In general, the progress made by the countries that have made positive changes has been gradual and not abrupt.

[8] Temple, J. Generalizations that Aren't? Evidence on Education and Growth, European Economic Review, Vol. 45, No.4-6, 2001, pp. 905-918.

[9] Pritchett, L. Where has all the education gone?, World Bank Economic Review, Vol.15, 2001, pp. 367-391.

[10] Hanushek, E. A., \& Woessmann, L. Do better schools lead to more growth? Cognitive skills, economic outcomes, and causation, Journal of Economic Growth,Vol.17, 2012, pp. 267-321. DOI 10.1007/s10887-012-9081-x.

[11] Hanushek, E. A., \& Woessmann, L. The Knowledge Capitak of Nations: Education and the Economics of Growth, 2015, Cambridge, MA : MIT press.

[12] Hanushek, E. A., \& Woessmann, L. How much do educational outcomes matter in OECD countries?, Economic Policy, Vol.26, No.67, 2011, pp. 427-491.

[13] Mourshed, M., Chijioke, C., Barber, M. (2010) : How the world's most improved school systems keep getting better. London : McKinsey\&Company.

[14] Hanushek, E.A. \& Kimko, D.D. Schooling, labor force quality, and the 
growth of nations, American Economic Review, Vol. 90, No. 5, 2011, pp. 11841208.

[15] Börsch-Supan, A. A model under siege: A case study of the German retirement insurance system, Economic Journal, Vol.110, No.461, 2000,

pp. 24-45. https://www.jstor.org/stable/2565940.

[16] Hagist, Ch., Klusen, N., Plate, A., \& Raffelhüschen, B. Social health insurance: The major driver of unsustainable fiscal policy?, CESifo Working Papers, 1574, 2005.

[17] Lopez, H.. The Social Discount Rate: Estimates for Nine Latin American Countries, 2008, World Bank WPS4639.

[18] Humavindu, M. N. Estimating national economic parameters for Namibia,2010, Development Bank of Namibia.

[19] Bah, M. \& Diop M. B. Détermination du taux d'actualisation sociale des projets d'investissement public au Sénégal, Planning paper, No.1, 2015. Direction de Planification.

[20] Kula, E. Social Interest Rate for Public Sector Projec Appraisal in the United Kingdom, the United States and Canada. Project Appraisal, Vol.2, No.3, 1987, pp. 169-174.

[21] Arrow, K. J. Intergenerational equity and the rate of discount in long-term social investment. Paper presented at the IEA World Congress. $1995 . \quad$ http:www econstanford.edu/faculty/workp/swp97005.pdf

[22] Aylward, B. \& Porras, I.T. An Analysis of Private and Social Discount Rates in Costa Rica, CREED Working Paper Series No 21. IIED, London, and IVM, Amsterdam. 1998.

[23] World Bank. World Development Indicators, 2018.

[24] CSEFRS. La mise en ouvre de la charte nationale d'éducation et de formation 2000-2013, acquis, déficits et défis, 2014, rapport analytique.

[25] Errihani, M. (2008): Language policy in Morocco: implications of recognizing and teaching Berber, Saarbrucken: VDM Verlag.

[26] Akesbi A. Quelle gouvernance pour une Education de qualité au Maroc ?. Dans Mieux gouverner l'école, Economia, CESEM, 2015, pp. 18-27.

[27] Chisag, J., Diaz, N., Calderon, F., Cruzado, F., Pisuna, F., Carate, M., Baylon, A. \& Ortiz, O. The Technology Acceptance Model in the Collaborative Learning of Web 2.0, Web 3.0 and Web 4.0: Higher Education Case Study, WSEAS Transactions on Environment and
Development, ISSN / E-ISSN: 1790-5079 / 2224-3496, Volume 16, 2020, Art. \#70, pp. 680-688.

[28] Gontareva, I., Maryna, B., Babenko, V., Perevozova, I., Mokhnenko, A. Identification of Efficiency Factors for Control over Information and Communication Provision of Sustainable Development in Higher Education Institutions, WSEAS Transactions on Environment and Development, ISSN / EISSN: 1790-5079 / 2224-3496, Volume 15, 2019, Art. \#63, pp. 593-604.

[29] Li, K., Zhang, P., Hu, B., Burchinal, B., Fan, X.\& Qin, J. Testing the 'thrsholds' of preschool education quality on child outcomes in China. Early Childhood Research Quarterly, Vol. 47, 2019, pp. 445456.

\section{Creative Commons Attribution License 4.0} (Attribution 4.0 International, CC BY 4.0)

This article is published under the terms of the Creative Commons Attribution License 4.0

https://creativecommons.org/licenses/by/4.0/deed.en_US 